\title{
Awareness and Self-Perceived Risk of Cervical Cancer among Women Living in Namuwongo, an Informal Settlement in Kampala, Uganda
}

Faith Nawagi ${ }^{1 *}$, John Mukisa ${ }^{2}$, Lynnette K Tumwine ${ }^{3}$, Rose C Nabirye ${ }^{3}$, Aidah Ajambo ${ }^{4}$, Denis L Bukenya ${ }^{5}$ and Amos D Mwaka

${ }^{1}$ Euclid University, Global Health Institute, Uganda

${ }^{2} U$ ganda Case Western Reserve University Research collaboration, Uganda

${ }^{3}$ Makerere University College of Health Sciences, Uganda

${ }^{4}$ Makerere University Johns Hopkins Research Collaboration, PMTCT program, Uganda

${ }^{5}$ Naguru Teenage Information and Health Centre, Uganda

\begin{abstract}
Background: Cervical cancer remains one of the leading causes of morbidity and mortality among women of reproductive age in sub Saharan Africa. However there is limited data on the level of awareness and perceived risk among women in peri urban slums of which most of the occupants are mainly women of reproductive age.
\end{abstract}

Methods: We carried out a population based cross-sectional study in Namuwongo, a peri urban slum in Kampala in 2016. Data was collected using a pretested interviewer administered questionnaire, entered and analyzed using SPSS 22.0

Results: Most participants, 259/311 (83.3\%) had heard about cervical cancer and (87.5\%) knew that cervical cancer can be prevented by early detection. Their main sources of information included Media such as radio and TV $(47.6 \%)$ and healthcare professionals at the health facility $(37.6 \%)$, friends and family $(14.1 \%)$. Almost half of the participants $(47.9 \%)$ didn't know about the possibility of prevention of cervical cancer through HPV vaccination. About $219 / 311(70.4 \%)$ perceived themselves to be at risk for cervical cancer in this study. Although majority had heard about cervical cancer, $209(67.2 \%)$ didn't know of any signs and symptoms of cervical cancer and the mean age of HPV vaccination mentioned was $2.41( \pm 0.77)$, much younger than the current recommended age category of 10-14 years. The mean age for starting screening was $10.77( \pm 9.87)$ compared to the normal recommended age of screening 21 and above.

Conclusion: Most of participants in this study had heard about cervical cancer although their knowledge of symptoms, preventive measures and importance of cervical cancer screening was low. Majority of the women perceived that they were at risk of developing cervical cancer although they were hardly knowledgeable of any reasons for their perceptions. There is need for more public awareness campaigns to provide detailed in-depth information to enhance knowledge on cervical cancer in informal settlements like slum populations.

Keywords: Cervical cancer; Perception; Knowledge; Cancer spread; Uganda

Abbreviations: HPV: Human Papilloma Virus; HIV: Human Immunodeficiency Virus; SD; Standard Deviation: VHTs: Village Health Teams

\section{Introduction}

Globally, more than 500,000 women develop cervical cancer annually and about 260,000 of these women die of the disease [1,2] Uganda has the highest burden of cervical cancer in the East African region, with an incidence rate of 44.4 per 100,000 women compared to the regional and worldwide incidence of 42.7 per 100,000 and 14.0 per 100,000 , respectively [3-5]. In Uganda, cervical cancer is the most common cancer among women aged 15 to 44 years [6]. The high incidence of cervical cancer has been attributed to several factors including scarce and inadequate screening services; high prevalence of sexually transmitted diseases including, HIV/AIDS, Human Papillomavirus Infection (HPV), early onset of sexual activity; polygamy; and high parity [6]. Poverty, low education levels, and gender inequalities are also important contributing factors to the high incidence and mortality of cervical cancer in Uganda [7]. This high disease burden among economically active young women undermines their reproductive and economic potential, leading to high losses to the affected families and the nation at large. In addition, majority of cervical cancer patients, in the low and middle-income countries including Uganda, are diagnosed with advanced stage diseases and experience poor survival [8-10]. Over, $80 \%$ of women with cervical cancer in Uganda are diagnosed with advanced stage disease; thus undermining the benefits expected from available treatment modalities $[4,11,12]$. A plethora of barriers including limited awareness of cervical cancer symptoms and signs, misattribution of symptoms to other illnesses, poor access to health services, and health professionals', limitations in diagnosing cervical cancer account in part for advanced stage cervical cancer at diagnosis and poor survival in the LMICs including Uganda [13-16]. Recent studies in sub Saharan Africa and Uganda, show that women's low self-perceived risk of cervical cancer and improper diagnosis by healthcare professionals in women with symptoms of cervical cancer lead to delayed diagnosis and advanced stages [15,17]. Low self-perceived risk for cervical cancer potentially leads women to

*Corresponding author: Faith Nawagi, GEMx Africa Representative, Makerere University College of Health Sciences, Department of Pharmacy 2nd Floor Room 3, Uganda, Tel: 256775491447; E-mail: fnawagi@gmail.com

Received October 16, 2017; Accepted October 23, 2017; Published October 30, 2017

Citation: Nawagi F, Mukisa J, Tumwine LK, Nabirye RC, Ajambo A, et al. (2017) Awareness and Self-Perceived Risk of Cervical Cancer among Women Living in Namuwongo, an Informal Settlement in Kampala, Uganda. J AIDS Clin Res 8: 741 doi: $10.4172 / 2155-6113.1000741$

Copyright: ( 2017 Nawagi F, et al. This is an open-access article distributed unde the terms of the Creative Commons Attribution License, which permits unrestricted use, distribution, and reproduction in any medium, provided the original author and source are credited. 
take symptoms of cervical cancer as due to other more common and benign illnesses. The women more often become less likely to pay keen attention to and seek appropriate care for symptomatic cervical cancer.

The mortality due to cervical cancer is extremely high in Uganda with 21.9 per 100,000 women dying annually from cervical cancerrelated causes compared to 27.2 per 100,000 and 6.8 per 100,000 women in the East Africa region and worldwide respectively $[4,18]$. In developed countries, cervical cancer has become a curable disease with only $7.5 \%$ mortality among those with the disease $[3,19]$. The low incidence and mortality from cervical cancer in the developed countries has been attributed to several aspects including awareness of cervical cancer risk factors and symptoms in the general public, establishment of organized population-based cervical screening programs, prompt health seeking and early detection of invasive cervical lesions and availability of appropriate treatment for precancerous and invasive cervical cancer lesions $[20,21]$. In response to the high incidence and mortality from cervical cancer, the Ugandan Ministry of Health formulated policy and guidelines for cervical cancer in 2010. These include prevention through HPV vaccination of girls aged 15 years and above, screening and early treatment for women with precancerous lesions using cytopathology examination, visual inspection with acetic acid (VIA) and cryotherapy and appropriate management of women with invasive cervical cancer. However, financial constraints, lack of trained staff, unavailability of vaccines in peripheral areas and in slum populations among others have made full policy implementation difficult $[7,22,23]$. These structural constraints are made worse by the fact that most Ugandan women are unaware of the predisposing factors to cervical cancer and importance of timely screening, early diagnosis and prompt treatment of symptomatic cervical cancer [24]. In addition, most women in Uganda do not perceive themselves to be at risk of getting cervical cancer and have immense fear of being diagnosed with the disease $[6,24,25]$. These factors in combinations probably explain in part the low level of screening in Uganda and other African countries [26,27]. Notably, only $2.8 \%$ of women in the suburban slum of Namuwongo where we conducted this study self-reported having ever screened for cervical cancer [23]. We therefore carried out a population-based study to assess the awareness and self-perceived risk to cervical cancer among the women in the reproductive age living in Namuwongo slum located in the suburbs of Kampala, Uganda. We hope findings from this study will inform targeted interventions to increase proportions of women undergoing cervical screening as well as promote early detection of symptomatic cervical cancer in informal settlements like slums in Uganda and other developing countries.

\section{Methods}

\section{Study design and setting}

This was a semi-structured questionnaire-based cross sectional study conducted in Namuwongo, a peri-urban Kampala city slum in Uganda. Namuwongo is two kilometers from the city Centre, in Makindye Division. The slum population is clustered along the railway line into four zones namely: Namuwongo Zone A, Namuwongo Zone B, Kanyogoga and Yoka [23].

There are about 20,000 people living in this slum area; women account for about $78 \%$ of the population. Most women in this area are poor, live in makeshift temporary shelters, have many children, and are unemployed or engaged in casual jobs in the city Centre [23]. The slum is served by a government Health Centre III and two major private hospitals.

\section{Study population and sample size}

We included women aged 21-65 years who were willing to provide informed written consent or thumb print following invitation and explanation of the study objectives. Women who were critically sick and or with history of mental illness were excluded to ensure valid responses to the survey questions as being critically ill and mental illness may alter one's ability to provide coherent response to the various questions asked We included 331 women identified with help of community local council leaders, Village Health Teams (VHTs) as residents of Namuwongo for more than six months. Sample size estimation was based on a similar study in Dares Salaam, Tanzania with a prevalence of awareness of cervical screening and knowledge about cervical cancer of $52.8 \%$ of women [27]. We assumed a power of $80 \%$ and level of significance of 0.05 to obtain a sample size of participants.

\section{Sampling and recruitment of participants}

Multistage cluster sampling was used to select study participants. Each of the four zones in Namuwongo slum was divided into three sections. In each zone three streets were subsequently selected randomly. With the help of local council leaders and the VHTs, trained research assistants approached households and introduced themselves and the study purpose. The first household at the one end of a road was purposefully selected, and then subsequent households were selected by systematic random sampling of every fifth household along the road. When the research assistants reached the end of the street, they would make $90^{\circ}$ turn (consistently right or left depending on which side of the street they were following) to the length of the street and then continue sampling every fifth household away from the street till they would reach the edge of the inhabitable section of the zone, at which point they would make a $90^{\circ}$ turn and continue sampling till the whole zone was sampled. The research assistants would then move to the opposite side of the road and carry out the same sampling process before going on to another randomly selected street. This procedure was carried out till the estimated sample size was achieved.

\section{Data collection}

A pre-tested interviewer administered questionnaire adapted from a study on women's knowledge and attitudes towards cervical cancer prevention in Eastern Uganda was used to collect data [28]. The research assistants [20] administered the questionnaire, mostly in the local language, Luganda. The research assistants read out the questions and coded responses to the participants and ticked or recorded responses accordingly.

For the questions concerning risk factors and perceived causes, the research assistants did not prompt recall by reading out the options but ticked all coded responses as the participants mentioned them. The research assistants would prompt participants to mention as many risk factors/perceived causes as possible by asking for example, "what else do you think may also cause this cancer?" in order to avoid suggesting risk factors that participants would not have mentioned but for having suggested. Administration of questionnaires lasted about 45-60 min. This study was conducted for a period of 3 months where the first month involved community entry and understanding the leadership as well as ensuring megaphone communication was done for the residents to be aware of the study. The second month involved data collection, cleaning and entering while the third month involved data analysis and reporting of the findings to the community. The length of the study did not influence knowledge of the later respondents at any one point in time since data collection was done in a close and short time duration.

Information collected included social and demographic 
Citation: Nawagi F, Mukisa J, Tumwine LK, Nabirye RC, Ajambo A, et al. (2017) Awareness and Self-Perceived Risk of Cervical Cancer among Women Living in Namuwongo, an Informal Settlement in Kampala, Uganda. J AIDS Clin Res 8: 741. doi: 10.4172/2155-6113.1000741

Page 3 of 6

characteristics, knowledge on cervical cancer signs and symptoms, risk factors and risk perception. Double data entry with SPSS version 22.0 was performed by two trained data clerks.

\section{Data management}

The anonymized data was analyzed using SPSS 22.0. Data was checked for completeness, cleaned and coded for analysis. Descriptive statistics such as mean, median and standard deviation (SD) were determined for continuous variables. Proportions were calculated as appropriate. A participant was considered to be aware of the signs and symptoms if they mentioned at least two signs and or symptoms known to be associated with cervical cancer.

\section{Ethical considerations}

Ethical approval was obtained from the Institutional Review Board of Mulago Teaching and Referral Hospital. Participants were informed of study objectives, consent procedures and potential benefits and harms. They were informed of their freedom to accept or decline participations and/or withdraw at any time without fear of any retribution. All participants provided written informed individual consents with a signature or thumb print. Privacy and confidentiality were ensured during data collection through utilization of individual questionnaire administration and use of study identification numbers other than participant's names. Completed questionnaires were kept under lock and key to maintain confidentiality.

\section{Results}

\section{Social and demographics characteristics of the participants}

A total of 311 participants of 324 contacted potential participants (96\% response rate) were interviewed. Nearly three quarters, $72.3 \%$ $(225 / 311)$ were married. The mean age ( \pm standard deviation, SD) was 27.7 ( \pm 1.33 ) years. About half of the participants (46.9\%) had attended secondary school as the highest level of education, and slightly over one fifth were formally employed. Reported mean monthly income was 193,370 Uganda Shillings (Table 1).

\section{Knowledge on cervical cancer}

Majority of participants, 259/311 (83.3\%) had heard about cervical

\begin{tabular}{|l|c|c|}
\hline Characteristic & Frequency (N) & Percentage (\%) \\
\hline Age, mean (SD) & 27.7 & \\
\hline Education & & \\
\hline No formal education & 30 & 9.7 \\
\hline Primary & 135 & 43.4 \\
\hline Secondary (Ordinary and Advanced) level & 130 & 41.8 \\
\hline Tertiary/University level & 16 & 5.1 \\
\hline Marital status & & \\
\hline Single & 58 & 18.7 \\
\hline Married & 225 & 72.4 \\
\hline Widowed & 7 & 2.3 \\
\hline Divorced & 21 & 6.6 \\
\hline Occupation & & \\
\hline Formal Employment & 239 & 76.8 \\
\hline No formal employment & $4( \pm 2)$ & \\
\hline $\begin{array}{l}\text { Number of people in household, mean } \\
\text { (SD) }\end{array}$ & 193,370 & \\
\hline Monthly income, mean, SD (UGX) & & \\
\hline
\end{tabular}

Table 1: Distribution of participants by the social demographic characteristics $\mathrm{N}=311$. cancer. Most of the participants (87.5\%) knew that cervical cancer can be prevented by early detection at the health facility (Table 2). Although majority had heard about cervical cancer, more than half (67.2\%) didn't know of any signs and symptoms of cervical cancer. About half of participants $(47.9 \%)$ didn't know about the possibility of prevention of cervical cancer through HPV vaccination. Among those who knew that vaccination could help in cervical cancer prevention, majority 158 (97.5\%) were not aware of the right age of vaccination. The mean age mentioned for vaccination is $2.41( \pm 0.77)$ years. Most participants also did not know the right age for starting cervical screening, thereby mentioning the mean age for starting screening as $10.77( \pm 9.87)$ years.

Regarding source of information about cervical cancer, the media was the most common reported medium (47.6\%), followed by healthcare professionals at the health facilities $(36.7 \%)$ and friends and family (14.1\%).

Only $33.3 \%$ of participants knew at least two or more symptoms/ signs of cervical cancer. The most common symptoms mentioned included vaginal bleeding 59 (57.2\%), abdominal pain $32(31.1 \%)$, foul smelling vaginal discharge $10(9.7 \%)$ and wounds on the cervix 3 (2.9\%).

\section{Knowledge on risk factors for cervical cancer}

Known risk factors for cervical cancer were correctly and consistently mentioned by only a few participants. Almost three quarters of the participants $222(71.4 \%)$ didn't know about HPV as a risk factor for cervical cancer development (Table 3).

\begin{tabular}{|l|c|c|}
\hline Knowledge on cervical cancer & Frequency (N) & Percentage (\%) \\
\hline Ever heard about Cervical cancer & & \\
\hline Yes & 259 & 83.3 \\
\hline No & 52 & 16.7 \\
\hline Information source about Cervical cancer & & 47.6 \\
\hline Media (radio, television, posters) & 148 & 36.7 \\
\hline Health Facility & 44 & 14.1 \\
\hline Friends/relatives & 5 & 1.6 \\
\hline School & & \\
\hline $\begin{array}{l}\text { Early detection of cervical cancer is } \\
\text { important in control of the disease }\end{array}$ & 272 & 87.5 \\
\hline Yes & 39 & 12.5 \\
\hline No & & 73.9 \\
\hline Cervical Cancer can be Cured & 230 & 26.1 \\
\hline Yes & 81 & 58.5 \\
\hline No & & 41.5 \\
\hline There is vaccination to prevent cervical & 162 & \\
\hline Yes & 149 & \\
\hline No & & \\
\hline $\begin{array}{l}\text { Knowledge on Age at vaccination (mean } \\
\text { age, SD }\end{array}$ & $2.41 \pm 0.77$ & \\
\hline $\begin{array}{l}\text { Knowledge on Age for frequency of } \\
\text { screening, mean, SD) }\end{array}$ & & \\
\hline $\begin{array}{l}\text { Knowledge of whether Cervical cancer can } \\
\text { be prevented }\end{array}$ & & \\
\hline Yes & & \\
\hline No & & \\
\hline $\begin{array}{l}\text { Knowledge of at least two symptoms of } \\
\text { cervical cancer }\end{array}$ & & \\
\hline Yes & & \\
\hline No & & \\
\hline Table & & \\
\hline
\end{tabular}

Table 2: Distribution of participants by their knowledge on aspects of cervical cancer $(\mathrm{N}=331)$. 


\begin{tabular}{|l|c|c|}
\hline $\begin{array}{l}\text { Knowledge on Risk factors for Cervical } \\
\text { Cancer: Do the following increase the } \\
\text { chance of a woman getting cervical } \\
\text { cancer? }\end{array}$ & Frequency (N) & Percentage(\%) \\
\hline Smoking cigarette/tobacco & & \\
\hline Yes & 211 & 67.8 \\
\hline No & 100 & 32.2 \\
\hline Human Papilloma Virus (HPV) infection & & \\
\hline Yes & 89 & 28.6 \\
\hline No & 222 & 71.4 \\
\hline Having multiple sexual partners & & \\
\hline Yes & 226 & 72.7 \\
\hline No & 85 & 27.3 \\
\hline Having recurrent sexually transmitted \\
disease (STDs)
\end{tabular}

Table 3: Distribution of participants by their knowledge on risk factors for cervica cancer $(\mathrm{N}=331)$

\section{Risk perception of cervical cancer}

Majority of participants, $219 / 311$ (70.4\%) perceived themselves to be at risk for cervical cancer. However, most of the participants, 200 (91.3\%) could not explain why they thought they were at risk or increased risk of developing cervical cancer.

\section{Discussion}

This study provides insight into awareness of women of relatively low socioeconomic status living in peri-urban slum of Kampala city regarding perceived self-risk for cervical cancer, awareness of risk factors and symptoms of cervical cancer, and perceptions about prevention and curability of cervical cancer. In most cities, women living in poor conditions are exposed to higher risk of sexually transmitted infections including HIV and the HPV that causes cervical cancer [29]. Such populations need to be aware of the increased risk as well as how to reduce their risk through HPV vaccinations and attendance of cervical screening as well as noticing symptoms early and seeking care promptly. Knowledge of early symptoms of cervical cancer is equally important for such women so that they may seek care when the disease is still in early stage and amenable to treatment. We found that majority of the participants had heard about cervical cancer. Their main sources of information included media such as radio and TV as well as from healthcare professionals at the health facility. Having ever heard about cervical cancer was found to be high in other studies in urban and peri-urban areas such in Dares Salaam and Kerala, with prevalence of $53.0 \%$ and $74.2 \%$, respectively [27,30]. In rural Uganda, two recent studies in Masaka [6] and northern Uganda [7] showed that more than $90 \%$ of participants had ever heard about cervical cancer. The study in Northern Uganda however included both male and female unlike our current study. The most common source of information about cervical cancer was the radio and healthcare professionals as in this study. This underscores the need to use these sources of communication whenever there is need to pass on information about cervical cancer.

Although majority had heard about cervical cancer, acknowledged the importance of early detection and agreed that the disease can be cured, only about half reported that vaccination can be a useful means to prevent cervical cancer. Primary prevention with vaccination against the high-risk HPV that causes cervical cancer is very critical in the long term control of cervical cancer. We found that the participants were not aware of the correct age for starting the HPV vaccination. Furthermore, majority did not know about the contribution of the sexually transmitted HPV virus and use of tobacco products in causation of cervical cancer. Only $28.5 \%$ and $67.8 \%$, respectively knew that these are risk factors for cervical cancer development. In addition, only 54.0\% acknowledged that having sexual intercourse with uncircumcised men increases a woman's risk for developing cervical cancer. Similarly, low levels of HPV awareness was also found in northern, eastern Uganda and Botswana $[7,29,31,32]$. Clearly this widespread low levels of awareness about the HPV and vaccination against the HPV as primary control measure for cervical cancer is concerning. Knowledge about the role of the HPV in causing cervical cancer has been low even in the developed countries, especially when the vaccine was not widely available [7]. It is possible that when the HPV vaccine becomes readily available, women will get to know about it and the right age for vaccination. Governments and development partners therefore need to work conscientiously to make this primary means of prevention available to local communities, especially those at higher risk of developing the disease.

Knowledge of risk factors is important in preventing exposures and thus reducing the chance of developing a disease [33]. We found that the majority of the participants (87.5\%) knew that early detection through screening is important in prevention of cervical cancer. However the mean age mentioned for starting cervical cancer screening was inappropriate. Most of the participants also reported an inappropriate age for starting HPV vaccinations. A study done in eastern Uganda also found similarly low level of awareness about the appropriate age for vaccination and cervical screening [28]. These deficiencies may be related to the inadequate or inappropriate knowledge of the risk factors for cervical cancer development or because of confusing screening and vaccination against the HPV with some other interventions against sexually transmitted infections. Clear communications about health interventions in the languages well understood by the target population, is important for appropriate transfer of knowledge in the desired interventions

We found $70.4 \%$ of the participants perceived themselves at risk of developing cervical cancer. They would most likely adopt the appropriate preventative measures and early detection strategies if they can access them easily at free or affordable costs at the point of care. This awareness could have arisen from the reported common sources of knowledge about cervical cancer - the media and healthcare personnel. Relatively high number of media campaigns has been going on in the study area and other locations in and around the city geared towards promoting cervical screening and early detection of precancerous and invasive cervical lesions.

\section{Strength and Limitation of the Study}

This was a population-based study conducted among women at relatively higher risk for developing cervical cancer. Results from this study provide important insights for design of targeted interventions 
Citation: Nawagi F, Mukisa J, Tumwine LK, Nabirye RC, Ajambo A, et al. (2017) Awareness and Self-Perceived Risk of Cervical Cancer among Women Living in Namuwongo, an Informal Settlement in Kampala, Uganda. J AIDS Clin Res 8: 741. doi: 10.4172/2155-6113.1000741

Page 5 of 6

for the control of cervical cancer in peri-urban slums with similar characteristics. The study has some limitations; first, we included participants from only one slum, Namuwongo, Kampala Uganda. This potentially limits the generalizability of findings to the extent proportional to the differences between the slums in Kampala. The results are also not generalizable to women not living in slums. The lack of a standardized awareness measurement questionnaire on cervical cancer in the sub Saharan Africa limits comparability of the findings across studies in Africa. Adapting questionnaires used by other studies in the region supports comparability of findings. However, the long term solutions to comparability challenge is the development of an African Cancer awareness Measurement tool similar to the UK Cancer awareness Measurement (CAM) tool that are used by all researchers measuring cancer awareness across the content.

\section{Conclusion}

The majority of participants in this study had heard about cervical cancer although their knowledge of symptoms, preventive measures and importance of cervical cancer screening was poor. Majority of the women perceived that they were at risk of developing cervical cancer. There is need for more public awareness campaigns to provide appropriate information to enhance knowledge on cervical cancer and promote risk preventive measures, cervical screening and prompt cancer detection in slum populations.

\section{Recommendations}

There is need for further investigation in other slums in Uganda to establish the extent to which the slum populations are knowledgeable about cervical cancer and how they contribute to the total country wide prevalence of cervical cancer which is still high. This will enable prioritization of interventions and probably establish which populations need more attention. A similar study should be done among men living in slums as they play a big role in decision making for women in seeking health care services.

\section{Ethical Considerations}

Ethical approval was obtained from the Institutional Review Board of Mulago Teaching and Referral Hospital. All participants provided written informed individual consents with a signature or thumb print.

\section{Availability of Data and Materials}

Data is available upon request from the corresponding author.

\section{Funding}

The funding for this study was gratefully provided by the Global Health Education and Training Services (GHETS) through the Women Health Task Force (WHTF) for the Network towards Unity for Health (TUFH).

\section{Authors Contributions}

FN and JM conceived the study, contributed to its design, data collection, and analysis and drafted the manuscript. LKT, RCN, AA, DB, ADM contributed in designing the study, data analysis and critical review of the manuscript. All authors read and approved the final manuscript.

\section{Acknowledgement}

We are indebted to the Namuwongo slum leaders most especially the chairpersons and the Village Health Team Representatives (VHTs) for the cooperation that allowed us access to this community and conduct this research.

\section{References}

1. Ferlay J, Soerjomataram I, Dikshit R, Eser S, Mathers C, et al. (2015) Cancer incidence and mortality worldwide: Sources, methods and major patterns in GLOBOCAN 2012. Int J Cancer 136: E359-E386.
2. Stewart Bernard W, Wild Christopher P (2014) World Cancer Report 2014 Lyon: International Agency for Research on Cancer, World Health Organization.

3. http://globocan.iarc.fr/Pages/fact_sheets_population.aspx

4. Ministry of Health (MOH) (2006) Uganda Demographic Health survey (UDHS) Government of Uganda, Kampala.

5. WHO, ICO (2010) Human Papillomavirus and Related Cancers. Summary Report Update.

6. Twinomujuni C, Nuwaha F, Babirye JN (2015) Understanding the Low level of cervical cancer screening in Masaka Uganda using the ASE model: A community-based survey. PLoS ONE 10: e0128498.

7. Mwaka AD, Orach CG, Were EM, Lyratzopoulos G, Wabinga H, et al. (2015) Awareness of cervical cancer risk factors and symptoms: Cross-sectional community survey in post-conflict northern Uganda. Health Expect 23: 12382.

8. Wabinga $\mathrm{H}$, Ramanakumar AV, Banura $\mathrm{C}$, Luwaga $\mathrm{A}$, Nambooze $\mathrm{S}$, et al. (2003) Survival of cervix cancer patients in Kampala, Uganda: 1995-1997. Br J Cancer 89: 65-69.

9. Gondos A, Brenner H, Wabinga H, Parkin DM (2005) Cancer survival in Kampala, Uganda. Br J Cancer 92: 1808-1812.

10. Gondos A, Chokunonga E, Brenner H, Parkin DM, Sankila R, et al. (2004) Cancer survival in a southern African urban population. Int J Cancer 112: 860864.

11. WHO (2010) Human Papillomavirus and related cancers in world. Summary Report 2010.

12. http://www.rho.org/files/PATH_Uganda_cxca_strat_plan_2010-2014.pdf

13. Birhanu Z, Abdissa A, Belachew T, Deribew A, Segni H, et al. (2012) Health seeking behavior for cervical cancer in Ethiopia: A qualitative study. Int J Equity Health 11: 83 .

14. Kivuti-bitok LW, Pokhariyal GP, Abdul R, Mcdonnell G (2013) An exploration of opportunities and challenges facing cervical cancer managers in Kenya. BMC Res Notes 6: 136.

15. Van Schalkwyk SL, Maree JE, Wright SC (2008) Cervical cancer: The route from signs and symptoms to treatment in South Africa. Reprod Health Matters 16: 9-17.

16. Chirenje ZM, Rusakaniko S, Kirumbi L, Ngwalle EW, Makuta-tlebere P, et al (2001) Situation analysis for cervical cancer diagnosis and treatment in east central and southern African countries. Bull World Health Organ 79: 127-132.

17. Mwaka AD, Okello ES, Wabinga H, Walter FM (2015) Symptomatic presentation with cervical cancer in Uganda: A qualitative study assessing the pathways to diagnosis in a low-income country. BMC Womens Health 15: 15.

18. Bruni L, Barrionuevo-Rosas L, Serrano B, Brotons M, Cosano R, et al. (2014) Human papillomavirus and related diseases in Uganda: Summary report 2014 HPV Information Centre.

19. GLOBOCAN (2012) Estimated cancer incidence, mortality and prevalence worldwide in 2012: Uganda Factsheet. International Agency for Research in Cancer (IARC), WHO.

20. Parkin DM, Bray F, Ferlay J, Pisani P (2005) Global cancer statistics, 2002. CA Cancer J Clin 55: 74-108.

21. WHO (2002) Cervical cancer screening in developing countries. Report of a WHO Consultation. World Health Organization, Geneva 2002.

22. Screening and associated factors among women in Rural Uganda: A cross sectional study (2016) PLoS One 11: e0149696.

23. Kirabira P, Nagaddya T (2012) Situational Analysis of the health status of the slum dwelling population along the railway line in Bukasa Parish, Makindye Division-Kampala.

24. Lyimo FS, Beran TN (2012) Demographic, knowledge, attitudinal and accessibility factors associated with uptake of cervical cancer screening among women in a rural district of Tanzania: Three public policy implications. BMC Public Health 12: 22.

25. Abdullahi A, Copping J, Kessel A, Luck M, Bonell C (2009) Cervical screening: Perceptions and barriers to uptake among Somali women in Camden. Public Health 123: 680-685.

26. http://www.cervicalcanceraction.org/pubs/pubs.php 
Citation: Nawagi F, Mukisa J, Tumwine LK, Nabirye RC, Ajambo A, et al. (2017) Awareness and Self-Perceived Risk of Cervical Cancer among Women Living in Namuwongo, an Informal Settlement in Kampala, Uganda. J AIDS Clin Res 8: 741. doi: 10.4172/2155-6113.1000741

Page 6 of 6

27. Kahesa C, Kjaer S, Mwaiselage J, Ngoma T, Tersbol B, et al. (2012) Determinants of acceptance of cervical cancer screening in DaresSalaam, Tanzania. BMC Public Health 12: 1093.

28. Mukama T, Ndejjo R, Musabyimana A, Musoke D (2017) Women's knowledge and attitudes towards cervical cancer prevention: A cross sectional study in Eastern Uganda. BMC Women's Health 17: 9.

29. Johnson LF, Coetzee DJ, Dorrington RE (2005) Sentinel surveillance of sexually transmitted infections in South Africa: A review. Sex Transm Infect 81: 287-293.

30. Aswathy S, Mariya AQ, Beteena K, Leelamoni K (2012) Cervical Cancer screening: Current knowledge and practice among women in a rural population of Kerala. India. Indian J Med Res 136: 205-210.

31. Ndejjo R, Mukama T, Musabyimana A, Musoke D (2016) Uptake of cervical cancer screening and associated factors among women in Rural Uganda: A cross sectional study. PLoS ONE 11: e0149696.

32. Mingo AM, Panozzo CA, DiAngi YT, Smith JS, Steenhoff AP (2012) Cervical cancer awareness and screening in Botswana. Int J Gynecol Cancer 22: 638644.

33. World Health Organization (2014) Comprehensive cervical cancer control. A guide to essential practice: 2nd Edition. WHO, Geneva. 